Research Article

\title{
Dynamic Simulations of the Allam Cycle Power Plant Integrated with an Air Separation Unit
}

\author{
Dan Fernandes, Song Wang $\mathbb{D}^{\mathrm{D}}$, Qiang Xu, and Daniel Chen \\ Department of Chemical Engineering, Lamar University, Beaumont, TX 77710, USA \\ Correspondence should be addressed to Daniel Chen; daniel.chen@lamar.edu
}

Received 23 September 2019; Accepted 13 November 2019; Published 7 December 2019

Academic Editor: Xunli Zhang

Copyright (c) 2019 Dan Fernandes et al. This is an open access article distributed under the Creative Commons Attribution License, which permits unrestricted use, distribution, and reproduction in any medium, provided the original work is properly cited.

\begin{abstract}
The unprecedented rise in carbon dioxide levels due to anthropogenic activities, if left unchecked, can lead to increased global warming. Electricity and heat generation account for around $25 \%$ of this greenhouse gas emission. The Allam cycle, a new oxy-fuel power cycle that emits virtually no $\mathrm{CO}_{2}$ and $\mathrm{NO}_{x}$, is inherently integrated with an air separation plant. In this study, Aspen Plus Dynamics was used to model the integrated Allam power plant/air separation unit (ASU) with a high degree of heat and work integration. The steady-state model developed agrees with the model developed by Net Power. Regulatory and advanced PID controllers were implemented for major equipment to meet operation objectives. Controller set point change, power ramp down, and natural gas composition change were studied, and key plant performance indicators were monitored and analyzed. This study shows that the Allam cycle power plant integrated with an ASU is controllable with the proposed control strategy under a tightly integrated configuration.
\end{abstract}

\section{Introduction}

About $1 / 3$ of the US greenhouse gas emissions is due to the production of electricity. Fossil fuel combustion generates $2 /$ 3 of the electricity in the US, and this will not change significantly till 2040 because of the abundance of cheap natural gas in the US. These combustion processes generate carbon dioxide which is a potent greenhouse gas. The $\mathrm{CO}_{2}$ emission from the US power generation for the year 2017 was 1.8 billion tons. The amount of carbon dioxide in the atmosphere today is more than what it was 800,000 years ago according to ice core records document. According to a recent research, we have barely 11 years to drastically reduce our greenhouse gas emissions to avoid the detrimental impacts of the global temperature increase by $2^{\circ} \mathrm{C}$ equivalent to a carbon dioxide level of $450 \mathrm{ppm}$ in the atmosphere. One promising technology that can help reduce huge emissions from the fossil fuel power plants is carbon capture, utilization, and storage (CCUS). Carbon capture mainly consists of three methods: (1) precombustion; (2) postcombustion; (3) oxy-fuel combustion with $\mathrm{CO}_{2}$ recycle and capture. Precombustion is used in integrated gasification combined cycle (IGCC) where carbon dioxide is captured from the syngas before it enters the gas turbine. In postcombustion, the carbon dioxide gas is captured after combustion using a solvent, sorbent, or membrane. Oxy-combustion is combustion in the presence of oxygen, after which the concentrated carbon dioxide is captured and utilized for enhanced oil recovery, chemical feedstock, or sequestration. The drawback of the oxy-combustion carbon capture process is the required air separation unit and carbon dioxide compression and purification unit [1-5].

A new advanced oxy-power cycle with a high efficiency of $59.7 \%$ and zero $\mathrm{CO}_{2}$ and $\mathrm{NO}_{x}$ emission is the Allam cycle. This highly recuperative oxy-combustion cycle makes use of the recycled supercritical carbon dioxide (97\% recycled) to dilute the oxygen and natural gas to operate the combustor at high temperatures and high pressures. The remaining 3\% high-pressure/high-purity pipeline-grade $\mathrm{CO}_{2}$ is ready for transport, utilization, and subsurface storage. An integral part of this system is the air separation unit (ASU) which supplies high-purity oxygen to the combustor. This combination of the power plant with an ASU results in numerous interactions between the two plants that require an effective 
strategy for control. The performance indicators of process operations include sustainability and economics (i.e., energy). But there is always a conflict between sustainability and profitability $[6,7]$. The use of comprehensive control strategies will make the operation of power plants smooth and economical; however, it can lead to higher capital expenditures due to the cost of extra controllers and engineering efforts. Care should be taken to select the optimum number of controllers and a suitable control strategy to optimize plant operations and capital costs. To that end, the power plant/ASU operational parameters and constraints should be understood.

Even though a power plant is expected to be operated at its designed capacity, it should be able to be operated in off-design conditions. The off-design conditions, also known as the transient behavior of a system, are a result of process requirements, power plant operation mode, or the power load variations. Flexible and robust control schemes must be implemented for the Allam power plant/ASU with an intensive mass and energy integration where a disturbance such as load changes originating in one part of the plant can propagate through the entire network. Due to this intensive heat and work integration, the number of degrees of freedom in the selection of manipulated variables (MVs) is reduced $[8,9]$.

The ASU which is an integrated part of an oxy-combustion process should be able to handle the ramp rates of the power plant along with flexible process operations. The flexibility in operation is in part due to increased use of sporadic renewable energies such as wind and solar power connected to an electrical grid $[10,11]$. This causes the power plant to behave in a dynamic manner. To realize this, flexible operation poses a challenge to the controller design and implementation for both the ASU and the power plant, respectively. A top-down and bottom-up analysis can be used to design the control structure. The top-down analysis includes defining the objectives, identifying the manipulated variables based on the degrees of freedom available, and selecting suitable process variables for measurement. For the bottom-up design, a regulatory control is implemented for flow, pressure, and level control loops, respectively while for a supervisory role, a cascade and ratio control which is a part of the advanced PID control strategy is implemented $[12,13]$.

To the authors' best knowledge, there has not been any published dynamic or control strategy studies in the Allam power plant integrated with an ASU. The control strategy along with the selection of variables depends on the degrees of freedom available in the dynamic simulation along with a suitable control philosophy to adapt to set point (SP) changes and to reject the disturbances, respectively. In this paper, the steady-state simulation is described first, followed by equipment sizing, control strategy descriptions, and the dynamic simulation results.

\section{Methodology}

2.1. Methodology Framework. To design and implement controllers and control strategies for a dynamic system, the dynamic simulation is a vital tool. Furthermore, it leads to a better understanding of process responses to a certain set point (SP) or disturbance variable (DV) change and can enhance the safety and reliability of plant operations. It is also a cost-effective way to conduct a feasibility study on the implementation of controllers before a detailed Front End Engineering Design (FEED) study can be done or a pilot plant established. It can also serve as a useful training simulator for operators. In comparison, a steady-state model is not transient in nature and cannot help to detect or analyze the characteristics of a dynamic system $[14,15]$.

There are only a few suitable simulation tools available in the market which can handle a complex and difficult process like distillation, combustion, reactors, complicated chemistry, and heat and work integration between the process units or plants [16]. In this study, a steady-state simulation was carried out in Aspen Plus V.10, which was later imported into Aspen Plus Dynamics V.10. Two different property packages were used: Peng Robinson for the air separation unit and Soave-Redlich-Kwong for the Allam cycle. Aspen Plus Dynamics is an Aspen Tech's dynamic modelling kit which is useful to model process design and plant operational capabilities for petrochemical, chemical, and other industries [17]. Here, a steady-state simulation can be converted to a dynamic simulation by either choosing the "flow-driven" or "pressure-driven" model. In this dynamic study, a "flow-driven" solver that is suitable for a wide range of dynamic simulation applications was used. The steadystate simulation results were published elsewhere recently [5] and are described briefly in Section 2.2 to provide the baseline conditions for all set point changes and disturbances.

2.2. Steady-State Simulation of the Integrated Allam Cycle/ $A S U$. In this study, 145.8 tph of oxygen is required for the oxy-combustion process of the Allam cycle to combust 36 tph of natural gas. The ASU selected is a cryogenic twocolumn system, which generates an oxygen stream of $99.5 \%$ by mole purity and a nitrogen stream. There is a tight energy and mass integration of the two columns. It can also handle liquid products and large-volume gaseous products. Ambient air is sucked by the main air compressor (MAC), where it is subcooled by the exit streams of the low-pressure column in a main cryogenic heat exchanger. One part of the subcooled air is sent via an expander to the low-pressure column (LPC) and another part to the high-pressure column (HPC). The process stream from the bottom of the HPC (5.6 bar) is sent to the top of the LPC (1.2 bar) as reflux. The bottom stream of the LPC is pure $\mathrm{O}_{2}$, and the top stream of the LPC is $\mathrm{N}_{2}$. The gaseous oxygen (GOX) coming from the main cryogenic heat exchanger via the bottom of the LPC is compressed by an $\mathrm{O}_{2}$ compressor and sent to the combustor in the Allam plant [18].

The Allam cycle is a high-pressure, highly recuperated supercritical Brayton cycle. Here, a mixture of natural gas and oxygen is combusted in the presence of $\mathrm{CO}_{2}$ which acts as a diluent to reduce the adiabatic flame temperature of the combustor. The exit stream of the combustor at $1110^{\circ} \mathrm{C}$ is fed to the high-temperature, high-pressure Toshiba turbine. The 
exhaust of the turbine at around $745^{\circ} \mathrm{C}$ is then cooled in a recuperator which exchanges heat with the recycled $\mathrm{CO}_{2}$ stream to the combustor. Water is removed from the $\mathrm{CO}_{2}$ stream in a separator. The $\mathrm{CO}_{2}$ is compressed, and a large part of it (97\%) is recycled back to the combustor and 3\% is sent for enhanced oil recovery (EOR) or geological sequestration. For EOR, the purity of $\mathrm{CO}_{2}$ should be greater than $95 \%$, and for sequestration, it should be between $85 \%$ and $99 \%$ [19]. Figure 1 shows the block flow diagram of the integrated complex, and Table 1 shows the stream flow conditions for the steady-state simulation of the air separation unit. Table 2 shows the comparison of our work and the work of Allam et al. at steady state [5, 20, 21].

\subsection{Dynamic Simulation of the Integrated Allam Cycle/ASU.} To export the steady-state simulation to the dynamic simulation requires equipment sizing and rating. For the HPC and LPC, sizing involves the type of column to be specified (tray or packed), the design of tray, location of the feed tray, and flooding and weeping consideration. Sizing of the reflux drum and sump was done for the HPC, and sizing of the sump was done for the LPC. The sizing is based on a heuristic that $50 \%$ full corresponds to a $5 \mathrm{~min}$ of liquid holdup based on the total liquid entering or leaving the vessel. For a reflux drum, this is the sum of the liquid distillate and reflux, and for the sump, it is the liquid which enters the reboiler from the bottom tray $[22,23]$. Table 3 gives the rotating equipment specifications where the input of efficiency and number of stages was taken from the literature. Table 4 shows the HPC/LPC specifications. For the main cryogenic heat exchanger, a zone analysis was done for a single zone in the countercurrent mode.

Dynamic simulations with recycle streams can be difficult to converge due to interactions between different process units within a recycle loop and the slow recycle dynamics compared to the other part of the flow sheet. Recycles streams are also susceptible to instability and sensitive to the effects of external disturbances [24-26]. The zone analysis needs to be done for the recuperator before conversion to the dynamic state model. The separator which is used to separate the $\mathrm{CO}_{2}$ and $\mathrm{H}_{2} \mathrm{O}$ is sized to a length of $10 \mathrm{~m}$ and a diameter of $3 \mathrm{~m}$. The heat transfer option is set at a constant temperature at $17^{\circ} \mathrm{C}$ for the separator. Afterwards, the steady-state simulation is exported to the dynamic environment by selecting the flow-driven solver option.

2.4. Control Strategies and Controllers. The selection of control strategies is based mainly on the profitability and the maximum utilization of the available assets. Plants which have a high degree of heat/work integration and large recycle streams are more prone to interactions in a control loop along with reduced degrees of freedom, i.e., available manipulated variables. In dynamic studies, each MV consumes one degree of freedom that in turn determines the corresponding controlled variable $(\mathrm{CV})$. For this work, the selected MVs are deemed to be the most effective and most related to the targeted CVs. A layer of advanced PID control is implemented on top of regulatory control in a process known as integration of operational hierarchies for this work. Controller tuning was done using the internal model control (IMC) method to ensure stability and robustness for the control system.

2.4.1. Regulatory PID Control. The configurable PID controller is the workhorse of the process and power industry. PID controllers can be implemented without a model and can be tuned based on the speed of response, asymptotic behavior, and dead time $[27,28]$. PI controller is the most common form used while the derivative action is used only for reducing oscillation and the settling time because it amplifies the process noises. PI is extensively used for flow, pressure, level, composition, and temperature control loops.

In the ASU, the condenser pressure, reflux drum level, and the sump level in the high-pressure column (HPC) employ the PI controllers. Likewise, for the low-pressure column (LPC), the column pressure and sump level also use PI controllers. For the Allam power plant, the separator has a pressure and a level control, both are of the PI type. The most important PI controller in this simulation is the temperature controller (TIC-1) which maintains the temperature of the combustor exit gas to the turbine inlet. It is maintained by controlling the amount of $\mathrm{CO}_{2}$ exported to EOR/sequestration, which in turn controls the recycling of the $\mathrm{CO}_{2}$ back to the combustor. This $\mathrm{CO}_{2}$ is a diluent to reduce the adiabatic flame temperature of an oxy-combustion process operated near the stoichiometric ratio. This diluent also helps to control the reaction temperature by reducing the ignition delay time and flame speed [29].

2.4.2. Advanced PID Control (Ratio and Cascade). Ratio control is suitable for maintaining the specified ratio between a controlled stream and a wild stream such as fuel-toair ratio in a combustion process, blending ratio between two fuel components, and steam-to-feed ratio in a distillation tower [30]. In this study, a fuel-to-air ratio controller is deployed to maintain the stoichiometric ratio between the natural gas to the combustor and feed air to the main air compressor. Furthermore, to control the amount of methane slip from the combustor outlet, the methane composition controller (AIC-1) is cascaded to the ratio controller (RC-1) to provide an adjustable ratio. Figure 2 shows the control architecture for the integrated plants, and Table 5 gives the controller ID, controller type, process variable (PV)/manipulated variable (MV) involved, and the controller tuning.

\section{Results and Discussion}

3.1. Set Point Tracking of the Combustor Outlet Temperature Controller (TIC-1). The set point tracking is done for the combustor outlet temperature with a doublet set point change. The process variables monitored are

(i) The methane slip from the combustor

(ii) Temperature, pressure, and flow of the combustor outlet stream 

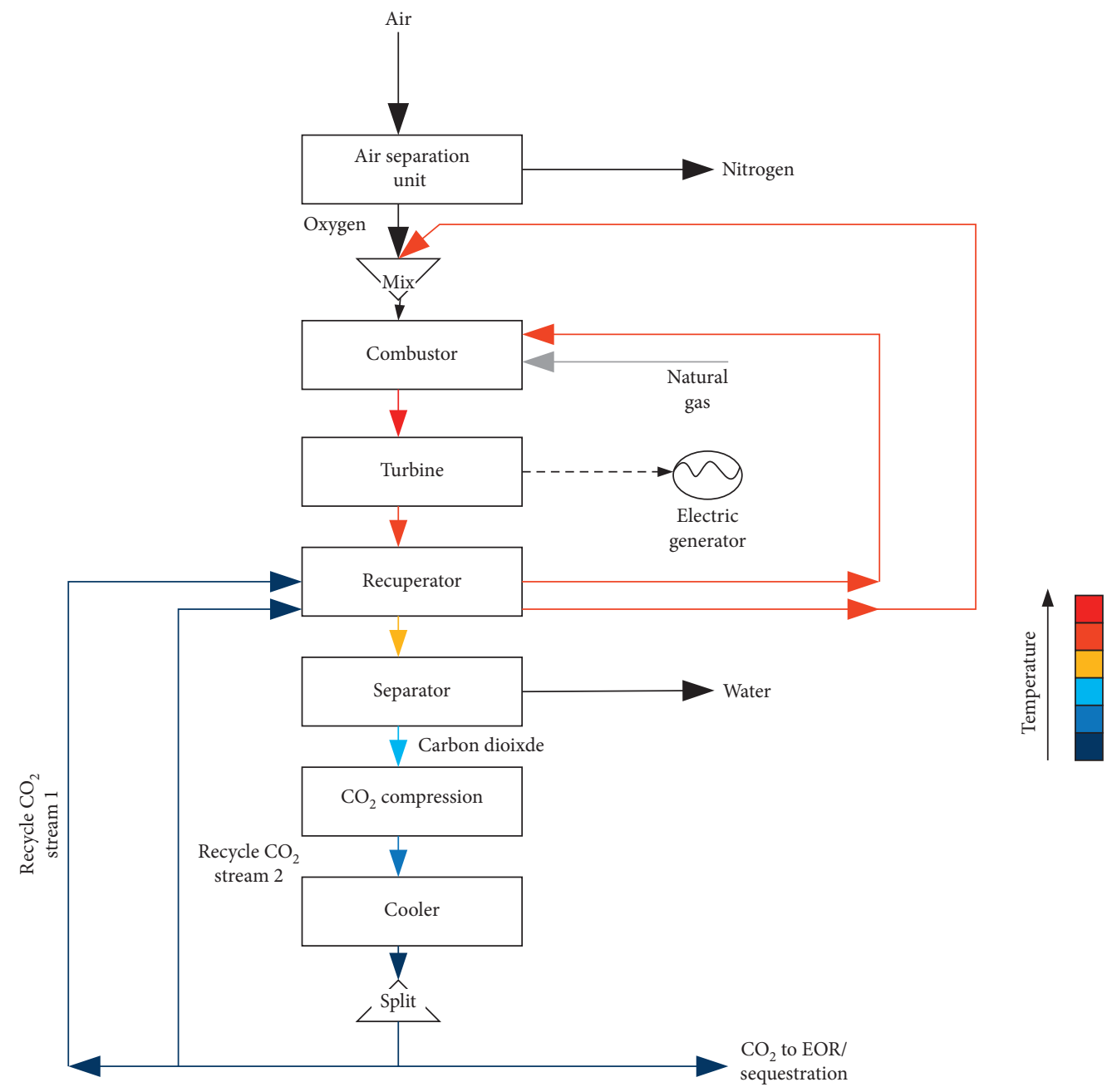

Figure 1: Block flow diagram of the integrated complex [21].

TABLE 1: Summary of major stream flow conditions for the air separation unit.

\begin{tabular}{lccc}
\hline $\begin{array}{l}\text { Stream } \\
\text { name }\end{array}$ & $\begin{array}{c}\text { Mass flow } \\
\text { rate } \\
(\mathrm{kg} / \mathrm{s})\end{array}$ & $\begin{array}{c}\text { Temperature } \\
\left({ }^{\circ} \mathrm{C}\right)\end{array}$ & $\begin{array}{c}\text { Pressure } \\
(\text { bar })\end{array}$ \\
\hline Air & 256.1 & 30 & 1.013 \\
To & 25.6 & 9.8 & 5.9 \\
Expander & 25.6 & -47.8 & 3.1 \\
To LPC & 230.5 & -177 & 5.9 \\
To HPC & 187.3 & -175.9 & 5.8 \\
HX IN & 187.3 & -177 & 5.8 \\
HX OUT & 217.04 & -190.8 & 1.4 \\
LPC TOP 1 & 217.04 & -188.8 & 1.4 \\
LPC TOP 2 & 39.06 & -176.2 & 1.9 \\
LPC BTM & 39.06 & -19.3 & 1.9 \\
$\mathrm{O}_{2}$ & 217.04 & -22.2 & 1.4 \\
$\mathrm{~N}_{2}$ & 10 & 38 & 30 \\
NG & 10 & 268 & 330 \\
TO COMB & & &
\end{tabular}

(iii) Temperature, pressure, and flow of the turbine exhaust stream

(iv) Water concentration in piped carbon dioxide line for sequestration/EOR (v) Net power available for export

A doublet set point change is performed on the combustor outlet temperature controller (TIC-1), which adjusts the piped carbon dioxide flow to regulate the $\mathrm{CO}_{2}$ flow back to the combustor. When the set point of the combustor outlet temperature control goes higher, recycle $\mathrm{CO}_{2}$ flow back to the combustor is reduced (more flow to pipeline for EOR/sequestration) to raise the combustor temperature.

The response of the combustor temperature to the set point change is smooth and does not exhibit any overshoot or oscillation. As the combustor outlet temperature (PV) increases from $1110^{\circ} \mathrm{C}$ to $1120^{\circ} \mathrm{C}$, there is no change in the concentration of $\mathrm{CO}_{2}$ and a marginal change in the water concentration in the piped carbon dioxide line. The net power decreases by $200 \mathrm{~kW}$ due to less recycle flow of $\mathrm{CO}_{2}$ to the combustor. The turbine exhaust temperature rises when the combustor outlet temperature is higher. Because the typical turbine inlet temperature range is high $\left(1100^{\circ} \mathrm{C}\right.$ to $\left.1200^{\circ} \mathrm{C}\right)$, the turbine exhaust goes to the high-temperature part of the recuperator made up of INCONEL alloy 617. The details are plotted in Figure 3. 
Table 2: Comparison of stream flow conditions at steady state $[5,20,21]$.

\begin{tabular}{|c|c|c|c|c|c|c|}
\hline \multirow{2}{*}{ Stream name } & \multicolumn{2}{|c|}{ Mass flow rate $(\mathrm{kg} / \mathrm{s})$} & \multicolumn{2}{|c|}{ Pressure (bar) } & \multicolumn{2}{|c|}{ Temperature $\left({ }^{\circ} \mathrm{C}\right)$} \\
\hline & Allam et al. & Fernandes et al. & Allam et al. & Fernandes et al. & Allam et al. & Fernandes et al. \\
\hline TURBINE INLET & 923 & 930.4 & $1000-2000$ & 1110 & $100-500$ & 300 \\
\hline EXHAUST & 923 & 930.4 & $500-1000$ & 745 & $30-70$ & 47 \\
\hline REOUT & 923 & 930.4 & $30-45$ & 45 & $30-70$ & 47 \\
\hline COMP IN & 909 & 909.5 & $17-50$ & 16.6 & 29 & 29 \\
\hline COOL 1 OUT & 909 & 909.5 & 23 & 23.1 & $40-100$ & 101 \\
\hline $\mathrm{CO}_{2} \mathrm{TO} \mathrm{EOR}$ & 28 & 28.1 & 23 & 23.1 & 100 & 101 \\
\hline RECYCLE $\mathrm{CO}_{2}$ & 881 & 881.4 & 16 & 15.9 & 100 & 101 \\
\hline $\mathrm{CO}_{2} \mathrm{TO} \mathrm{COMB}$ & 689 & 690 & 717 & 710 & $100-500$ & 315.9 \\
\hline $\mathrm{CO}_{2}+\mathrm{O}_{2} \mathrm{TO} \mathrm{COMB}$ & 233 & 230 & 717 & 711 & $100-500$ & 312 \\
\hline
\end{tabular}

TABLE 3: Rotating equipment specifications.

\begin{tabular}{|c|c|c|c|c|}
\hline Equipment name & Brake power (MW) & Shaft speed (rpm) & Efficiency (\%) & Stages \\
\hline MAC & 59.6 & 3600 & 80 & 2 \\
\hline EXPANDER & 1.5 & 3600 & 80 & 1 \\
\hline $\mathrm{O}_{2}$ Comp. & 19 & 3600 & 72 & 4 \\
\hline NG Comp. & 5.2 & 3600 & 72 & 4 \\
\hline Oxygen pump & 9.6 & 3600 & 77.6 & 1 \\
\hline Turbine & 464.5 & 3600 & 92.8 & 3 \\
\hline $\mathrm{CO}_{2}$ Comp. & 70.3 & 3600 & 72 & 2 \\
\hline Recycle pump & 21.2 & 3600 & 77 & 1 \\
\hline
\end{tabular}

TABLE 4: High-pressure and low-pressure column specifications.

\begin{tabular}{lcc}
\hline Specifications & High-pressure column & Low-pressure column \\
\hline Column internals & Tray & Tray \\
Packing type & Sieve & Sieve \\
Number of trayed stages & 39 & 55 \\
Total height (m) & 24 & 33.3 \\
Diameter (m) & 5.5 & 7.3 \\
Total pressure drop (bar) & 0.35 & 0.51 \\
\% approach to flood & 72.3 & 77.63 \\
Number of tray passes & 1 & 2 \\
Sump: height/diameter (m) & $5.42 / 2.71$ & $4.75 / 2.37$ \\
Reflux drum: height/diameter (m) & $9.64 / 4.82$ & N/A \\
\hline
\end{tabular}

3.2. Disturbance Rejection Performance of Various Controllers. In this section, the performances of the controllers to reject disturbances caused by natural gas composition change and power ramp downs in the integrated Allam power cycle/ASU are presented. The scenarios are

(i) Natural gas composition change

(ii) Plant ramp down

The process variables monitored are

(i) The methane slip from the combustor

(ii) Temperature, pressure, and flow of a given equipment under study

(iii) Carbon dioxide concentration in piped carbon dioxide line for sequestration/EOR

(iv) Water concentration in piped carbon dioxide line for sequestration/EOR (v) Turbine exhaust conditions

(vi) Net power available for export

3.2.1. Rejection of Natural Gas Composition Change. The composition of natural gas, which varies from one reservoir to another, can cause a disturbance to the power plant operation [31]. In this scenario, the percentage of methane in the gas was decreased from $97.5 \%$ to $87.5 \%$ by mass and ethane percentage was increased from $1.5 \%$ to $11.5 \%$ by mass at 2 hours into the simulation run.

This caused the turbine inlet temperature to drop from $1110^{\circ} \mathrm{C}$ to $1108^{\circ} \mathrm{C}$ momentarily, but the disturbance was quickly rejected by using the combustor outlet temperature controller (TIC-1), which reduced recycle $\mathrm{CO}_{2}$ flow to the combustor to recover the temperature of the combustor back to $1110^{\circ} \mathrm{C}$. The methane slip from the combustor also recovered back after a momentarily dip because of the 


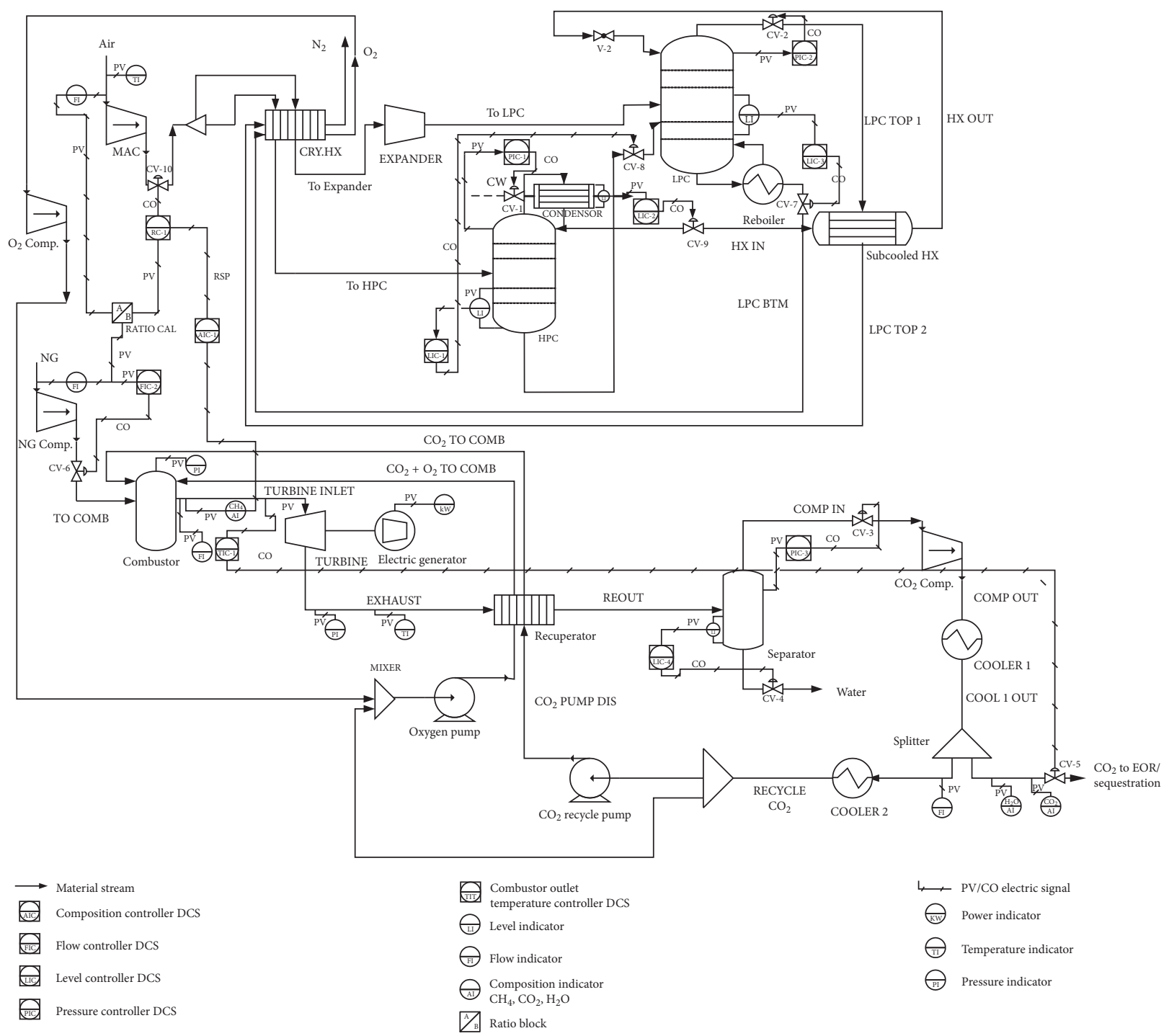

FIgURE 2: Plant-wide control architecture for integrated complex.

TABle 5: Controller specifications of the integrated Allam power plant/ASU.

\begin{tabular}{|c|c|c|c|c|c|}
\hline \multirow{2}{*}{ Controller ID } & \multirow{2}{*}{ Controller type } & \multirow{2}{*}{ PV } & \multirow{2}{*}{ MV } & \multicolumn{2}{|c|}{ Tuning parameters } \\
\hline & & & & $K_{\mathrm{C}}(\% / \%)$ & $\tau_{i}(\min )$ \\
\hline PIC-1 & PI & HPC column pressure & Condenser heat duty (CV-1 VP) & 20 & 12 \\
\hline LIC-1 & PI & HPC sump liquid level & HPC bottom flowrate (CV-8 VP) & 10 & 60 \\
\hline LIC-2 & PI & HPC condenser liquid level & HPC top flowrate (CV-9 VP) & 10 & 60 \\
\hline PIC-2 & PI & LPC column pressure & LPC top flowrate (CV-2 VP) & 20 & 10 \\
\hline LIC-3 & PI & LPC sump liquid level & LPC bottom flowrate (CV-7 VP) & 10 & 60 \\
\hline AIC-1 & PI & Combustor outlet methane slip & RSP to RC-1 & 0.01 & 0.5 \\
\hline $\mathrm{RC}-1$ & PI & NG/air ratio (in mass flow) & $\mathrm{CV}-10 \mathrm{VP}$ & 1 & 20 \\
\hline FIC-2 & PI & NG (in mass flow) & CV-6V P & 1 & 20 \\
\hline TIC-1 & PI & Combustor outlet temperature & Recycled $\mathrm{CO}_{2}$ flow (CV-5 VP) & 0.875 & 1.99 \\
\hline PIC-3 & PI & Separator top pressure & $\mathrm{COMP}$ in flow rate (CV-3 VP) & 20 & 12 \\
\hline LIC-4 & PI & Separator liquid level & Water mass flow rate $(\mathrm{CV}-4 \mathrm{VP})$ & 10 & 60 \\
\hline
\end{tabular}

$\mathrm{PV}$ : process variable; $\mathrm{MV}$ : manipulated variable; $\mathrm{CV}$ : control valve; VP: valve position; RSP: remote set point.

methane composition controller (AIC-1) cascaded to the fuel to the air ratio controller (RC-1). The carbon dioxide purity was unaffected, and water concentration dropped from $299.5 \mathrm{ppm}$ to $298.5 \mathrm{ppm}$. According to the Department of Energy (DOE) regulation, the water content in the pipeline should not exceed $500 \mathrm{ppm}$ to prevent hydrate 

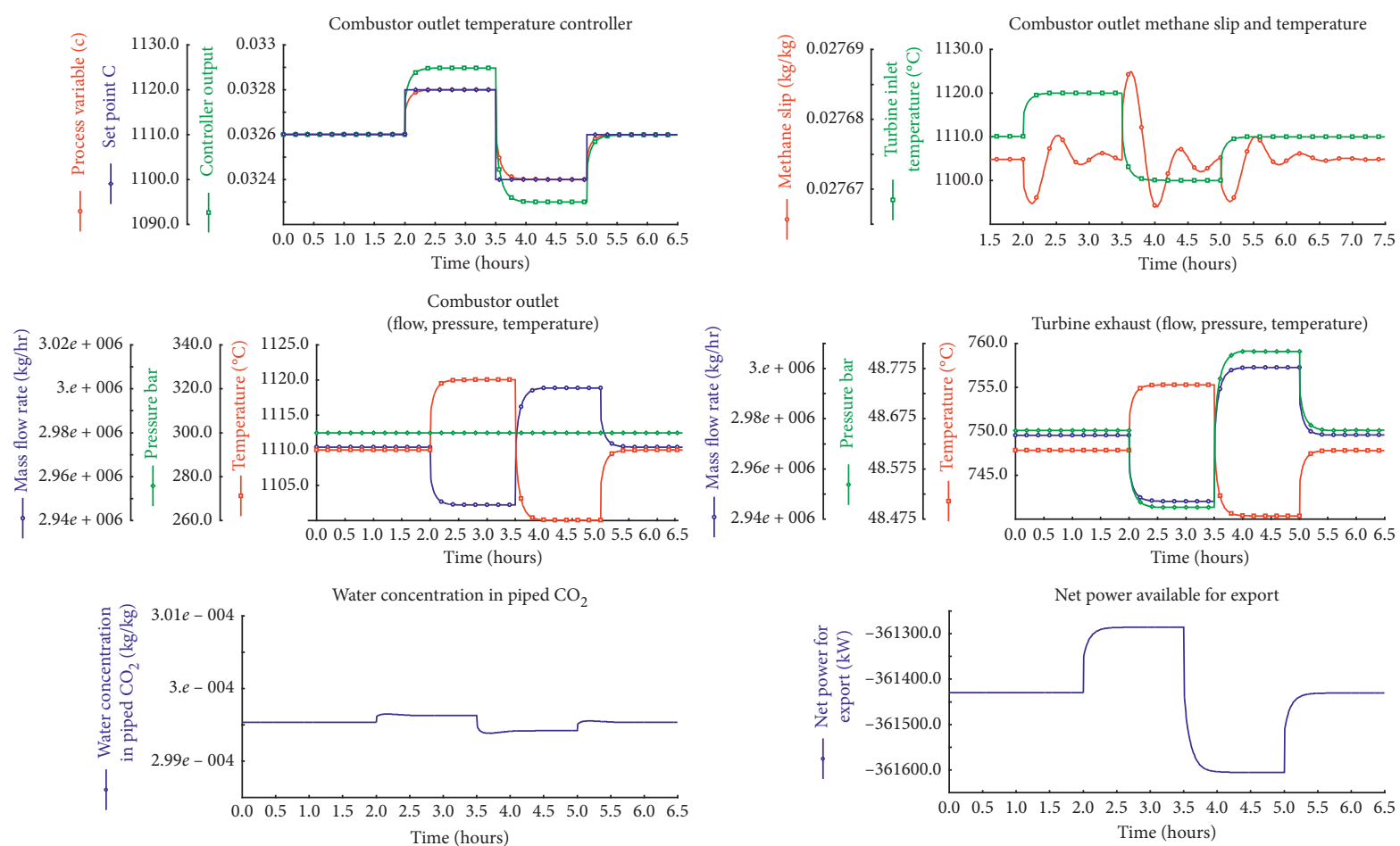

Figure 3: Response of the monitored process variables to a doublet set point change $\left(1110 \longrightarrow 1120 \longrightarrow 1100 \longrightarrow 1110^{\circ} \mathrm{C}\right)$ of the combustor outlet temperature controller (TIC-1).
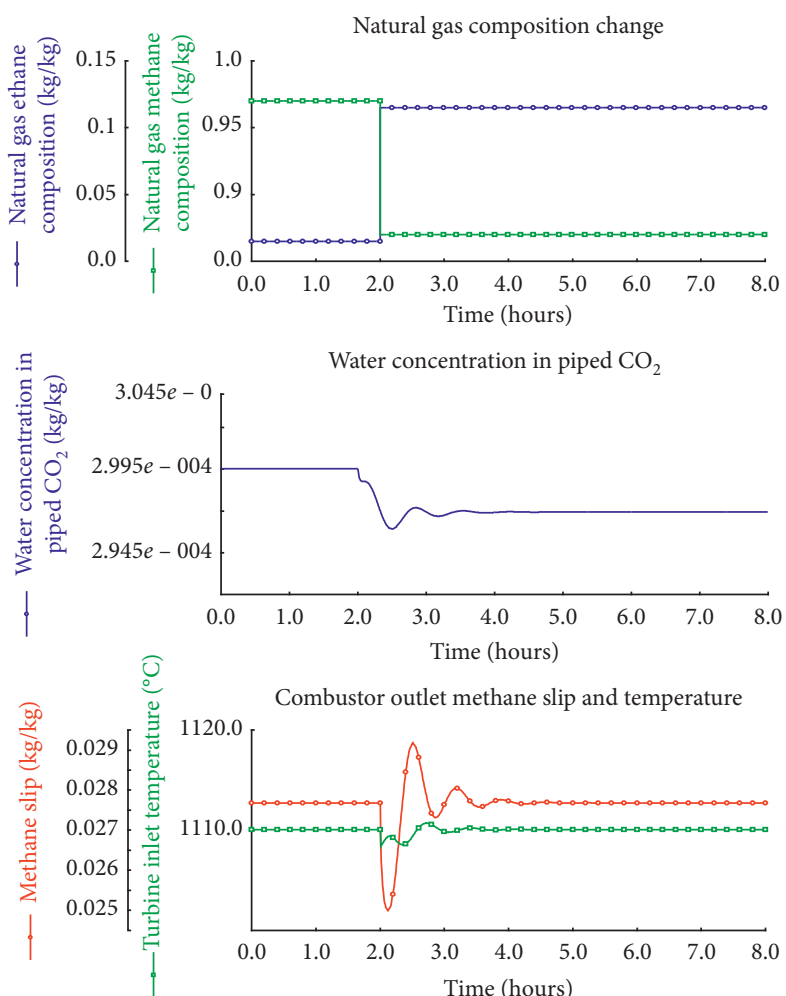

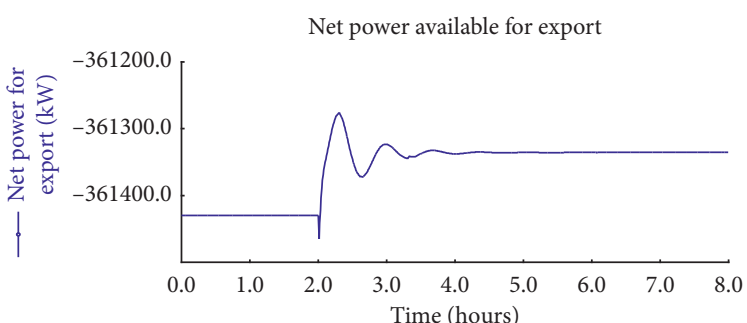

$\mathrm{CO}_{2}$ concentration in piped $\mathrm{CO}_{2}$
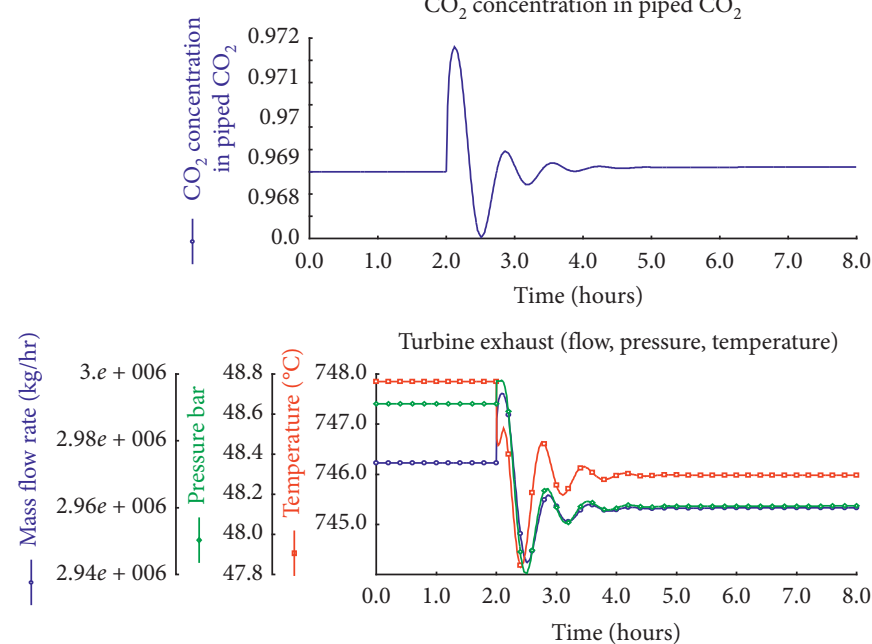

FIGURE 4: Response of the monitored process variables to natural gas composition change (methane from 97.5 mass $\%$ to 87.5 mass $\%$ and ethane from 1.5 mass\% to 11.5 mass\%).

formation and corrosion [32]. The change in natural gas composition caused a reduction in power by $100 \mathrm{~kW}$. Figure 4 shows the detailed plots.
3.2.2. Plant Ramp Down from Base Load (100\%) to Off-Peak Load (85\%). Power plants (natural gas, nuclear, and coal) are designed to run for 24 hours a day through most of the 

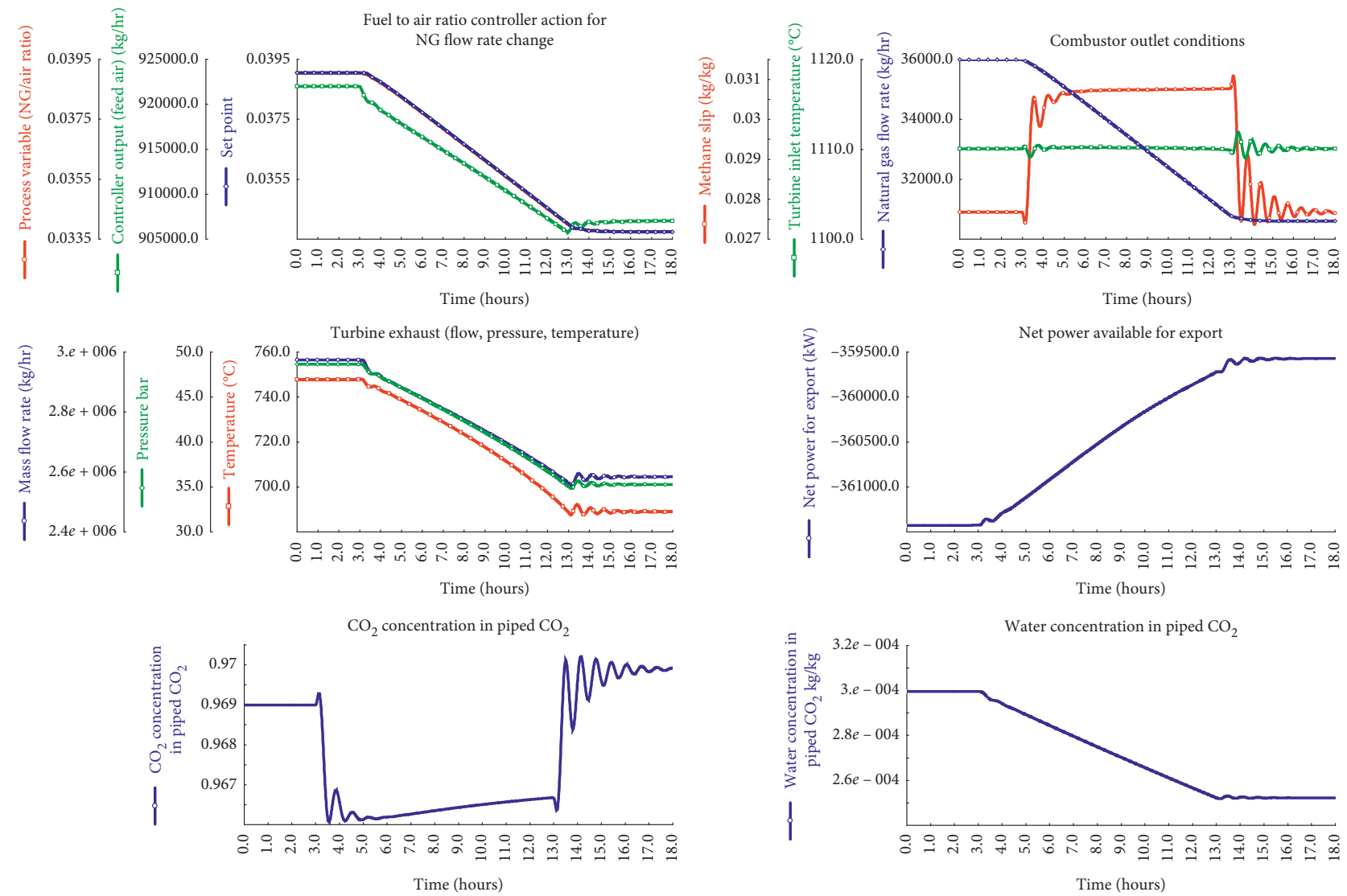

FigURE 5: Response of the monitored process variables to plant ramp down (100\% to $85 \%$ equivalent to change in natural gas flow rate $36000 \mathrm{~kg} / \mathrm{hr}$ to $30600 \mathrm{~kg} / \mathrm{hr}$ ).

year. This is the base load electricity supply to the grid. However, the increasing use of renewable energy like solar, wind, and hydroelectric power, even though favorable from the environmental standpoint, can cause supply issues due to their intermittent/seasonal nature. So, whenever the renewable energy comes online, the power plants must be able to ramp down to give first preference to the renewable energy supply to the electric grid.

In this study, the power plant complex is ramped down from $100 \%$ to $85 \%$ in ten hours (the natural gas flow rate is decreased from $36,000 \mathrm{~kg} / \mathrm{hr}$ to $30,600 \mathrm{~kg} / \mathrm{hr}$ ) using the controller FIC-2. The turbine inlet temperature was maintained at its set point by using the combustor outlet temperature controller (TIC-1). The methane composition controller (AIC-1), which is cascaded to the ratio controller (RC-1), was able to bring the methane slip to its set point after the ramp down. The concentrations of $\mathrm{CO}_{2}$ and water were within pipeline specifications during the ramp down. The net power for export has decreased by 1.86 MW. Figure 5 shows the detailed plots.

\section{Conclusion and Recommendations}

Dynamic simulations are indispensable for design, control, and economic/environmental impact studies. The baseline steady-state simulation for the Allam cycle is shown to be in good agreement with the work done by Net Power. This work is a follow-up study on our steady-state modelling of the integrated ASU/oxy-fuel Allam plant complex and presents for the first time the development of advanced control strategies and the dynamic set point tracking and disturbance rejection responses for such integrated complex.

The set point changes were made for the combustor outlet temperature controller. Furthermore, two disturbance scenarios: a change in natural gas composition and a plant ramp down to $85 \%$ load (e.g., to accommodate for renewable energy power inputs to the electric grid) were investigated. Important performance variables were monitored. Process plants with a recycle and a high degree of heat and work integration have a smaller number of degrees of freedom available for control. Our dynamic simulations show that the Allam cycle power plant integrated with an ASU is controllable with the proposed control strategy even under a tightly integrated configuration.

Since water concentration in the piped $\mathrm{CO}_{2}$ should not exceed $500 \mathrm{ppm}$ (to prevent pipeline corrosion), it is recommended to install a carbon dioxide processing unit (CPU) downstream in the event of large disturbances. An intermediate $\mathrm{O}_{2}$ tank to speed up the $\mathrm{O}_{2}$ response to $\mathrm{NG}$ supply changes also should be explored.

The development of further advanced control strategies including model predictive control (MPC), equipment failure scenarios, and scheduling/optimization for power load demand is recommended for future work. 


\section{Data Availability}

Previously reported data were used to support this study and were cited in relevant places within the texts as reference.

\section{Conflicts of Interest}

The authors declare they have no conflicts of interest.

\section{Acknowledgments}

The authors gratefully acknowledge the financial support from the Texas Air Research Center (TARC Grant numbers: 079LUB0096A and 117LUB0165A) and Lamar University Visionary Initiatives Program (Grant \#420065).

\section{References}

[1] P. Daoutidis, M. Zachar, and S. Jogwar, "Sustainability and process control: a survey and perspective," Journal of Process Control, vol. 44, pp. 184-206, 2016.

[2] M. P. S. Badger, T. B. Chalk, G. L. Foster et al., Insensitivity of Alkenone Carbon Isotopes to Atmospheric $\mathrm{CO}_{2}$ at Low to Moderate $\mathrm{CO}_{2}$ Levels, vol. 15, Copernicus Publications, Göttingen, Germany, 2019.

[3] U. Chrobak, Carbon Capture Could Keep Global Warming in Check-Here's How it Works, Bonnier Corporation, Winter Park, FL, USA, 2019, https://www.popsci.com.

[4] B. Jin, M. Su, H. Zhao, and C. Zheng, "Plantwide control and operating strategy for air separation unit in oxy-combustion power plants," Energy Conversion and Management, vol. 106, pp. 782-792, 2015.

[5] D. Fernandes, S. Wang, Q. Xu, R. Buss, and D. Chen, "Process and carbon footprint analyses of the Allam cycle power plant integrated with an air separation unit," Clean Technologies, vol. 1, no. 1, pp. 325-340, 2019.

[6] F. Alobaid, R. Postler, J. Ströhle, B. Epple, and H.-G. Kim, "Modeling and investigation start-up procedures of a combined cycle power plant," Applied Energy, vol. 85, no. 12, pp. 1173-1189, 2008.

[7] J. J. Siirola and T. F. Edgar, "Process energy systems: control, economic, and sustainability objectives," Computers \& Chemical Engineering, vol. 47, pp. 134-144, 2012.

[8] J. Y. Shin, Y. J. Jeon, D. Maeng, J. S. Kim, and S. T. Ro, "Analysis of the dynamic characteristics of a combined-cycle power plant," Energy, vol. 27, no. 12, pp. 1085-1098, 2002.

[9] P. J. Robinson and W. L. Luyben, "Integrated gasification combined cycle dynamic model: $\mathrm{H} 2 \mathrm{~S}$ absorption/stripping, water-gas shift reactors, and $\mathrm{CO}_{2}$ absorption/stripping," Industrial \& Engineering Chemistry Research, vol. 49, no. 10, pp. 4766-4781, 2010.

[10] B. Jin, H. Zhao, and C. Zheng, "Dynamic modeling and control for pulverized-coal-fired oxy-combustion boiler island," International Journal of Greenhouse Gas Control, vol. 30, pp. 97-117, 2014.

[11] T. Pourchto, F. Grainer, D. Goloubeveb, and A. Alekseev, "Oxy-combustion: an ASU integration option and improved operation flexibility," in Proceedings of the 3rd Oxyfuel Combustion Conference, Wuhan, China, Septmeber 2013.

[12] Y. Hu, X. Li, H. Li, and J. Yan, "Peak and off-peak operations of the air separation unit in oxy-coal combustion power generation systems," Applied Energy, vol. 112, no. 7, pp. 47754, 2013.
[13] S. Skogestad, "Control structure design for complete chemical plants," Computers \& Chemical Engineering, vol. 28, no. 1-2, pp. 219-234, 2004.

[14] B. Jin, H. Zhao, and C. Zheng, "Dynamic simulation of a conceptual 600 MWe oxy-fuel combustion power plant," in Proceedings of the 3rd Oxyfuel Combustion Conference, IEAGHG, Wuhan, China, Septmeber 2013.

[15] J. Lappalainene, H. Blom, and K. Juslin, "Dynamic process simulation as an engineering tool-a case of analyzing a coal plant evaporator," VGB Powertech, vol. 92, pp. 62-68, 2012.

[16] H. Mikkonen, J. Lappalainen, T. Pikkarainen, and R. Kuivalainen, "Modelling and dynamic simulation of the 2nd generation oxy fired power plant-oxidant fan failure case," Energy Procedia, vol. 114, pp. 561-572, 2017.

[17] Aspen Dynamics Help, "Version 10," Aspentech's Product Information, 2017, https://www.aspentech.com.

[18] D. R. Vinson, "Air separation control technology," Computers \& Chemical Engineering, vol. 30, no. 10-12, pp. 1436-1446, 2006.

[19] J. M. Race, B. Wetenhall, P. N. Seevam, and M. J. Downie, "Towards a $\mathrm{CO}_{2}$ pipeline specification: defining tolerance limits for impurities," in Proceedings of the Third International Forum on the Transportation of $\mathrm{CO} 2$ by Pipeline, Newcastle University, Newcastle upon Tyne, UK, June 2012.

[20] R. J. Allam, M. Palmer, J. Brown Jr., and G. Williams, "System and method for high efficiency power generation using a carbon dioxide circulating working fluid," Applicant: 8 Rivers Capital, LLC, Appl. No: 16/058474, 2018.

[21] R. Allam, S. Martin, B. Forrest et al., "Demonstration of the Allam cycle: an update on the development status of a high efficiency supercritical carbon dioxide power process employing full carbon capture," Energy Procedia, vol. 114, pp. 5948-5966, 2017.

[22] P. Mahapatra and B. W. Bequette, "Design and control of an elevated-pressure air separations unit for IGCC power plants in a process simulator environment," Industrial \& Engineering Chemistry Research, vol. 52, no. 9, pp. 3178-3191, 2012.

[23] W. L. Luyben, Distillation Design and Control Using AspenSimulation, vol. 146, John Wiley \& Sons, Hoboken, NJ, USA, 2nd edition, 2013.

[24] K. R. Jillson, V. Chapalamadugu, and B. E. Erik Ydstie, "Inventory and flow control of the IGCC process with $\mathrm{CO}_{2}$ recycles," Journal of Process Control, vol. 19, no. 9, pp. 1470-1485, 2009.

[25] A. Kumar and P. Daoutidis, "Nonlinear dynamics and control of process systems with recycle," Journal of Process Control, vol. 12, no. 4, pp. 475-484, 2002.

[26] D. P. Coffey and B. E. Ydstie, "Distributed control and realtime optimization of a chemical process," in Proceedings of the DYCOPS-5, Corfu, Greece, June 1998.

[27] J. A. Romagnoli and A. Palazoglu, Introduction to Process Control, CRC Press, vol. 211, 2nd edition, 2012.

[28] J. B. Riggs and M. Karim, Chemical \& Bio-rocess Control, vol. 241, Ferret Publishing, Boca Raton, FL, USA, 4th edition, 2016.

[29] F. B. Shareh, G. Silcox, and E. G. Eddings, "Calculated impacts of diluents on flame temperature, ignition delay, and flame speed of methane-oxygen mixtures at high pressure and low to moderate temperatures," Energy \& Fuels, vol. 32, no. 3, pp. 3891-3899, 2018.

[30] H. L. Wade, "Basic and advanced regulatory control: system design and application," in The Instrumentation, Systems and Automation Society, pp. 201-202, ISA Press, Research Triangle Park, NC, USA, 2nd edition, 2004. 
[31] S. Faramawy, T. Zaki, and A. A.-E. Sakr, "Natural gas origin, composition, and processing: a review," Journal of Natural Gas Science and Engineering, vol. 34, pp. 34-54, 2016.

[32] E. de Visser, C. Hendriks, M. Barrio et al., "Dynamis $\mathrm{CO}_{2}$ quality recommendations," International Journal of Greenhouse Gas Control, vol. 2, no. 4, pp. 478-484, 2008. 


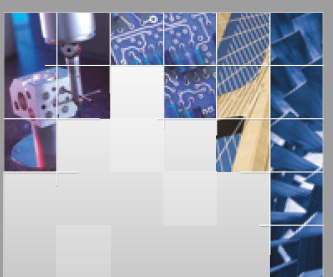

\section{Enfincering}
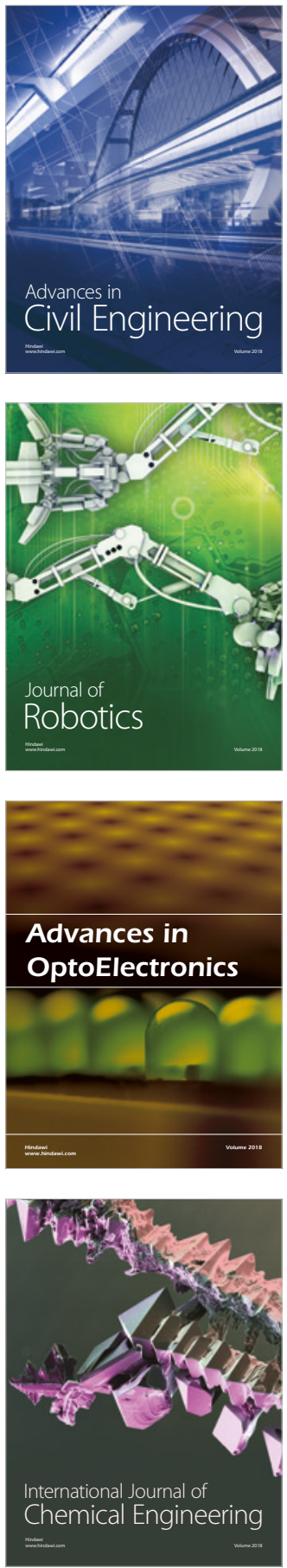

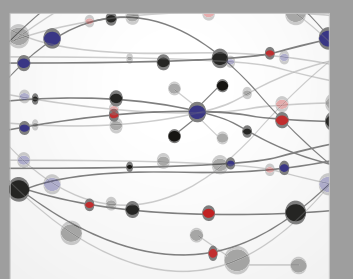

\section{Rotating \\ Machinery}

The Scientific World Journal

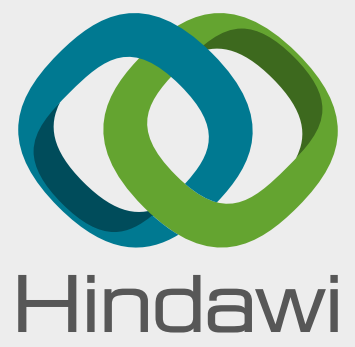

Submit your manuscripts at

www.hindawi.com
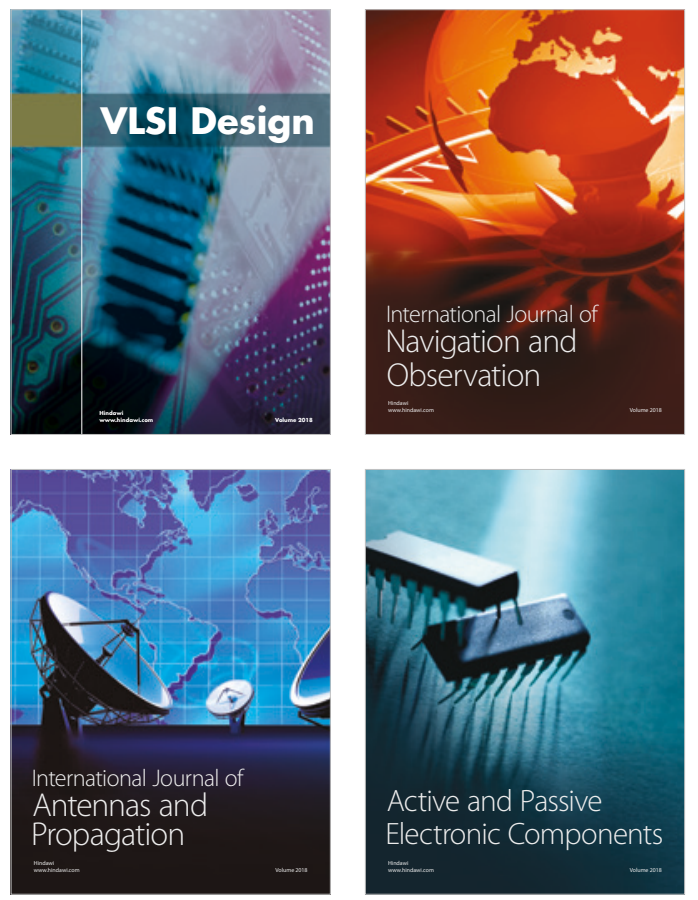
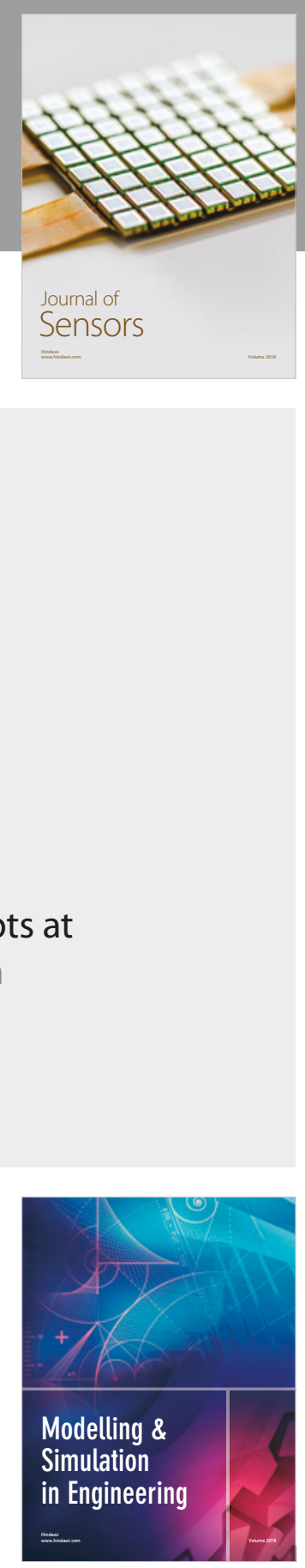

\section{Advances \\ Multimedia}
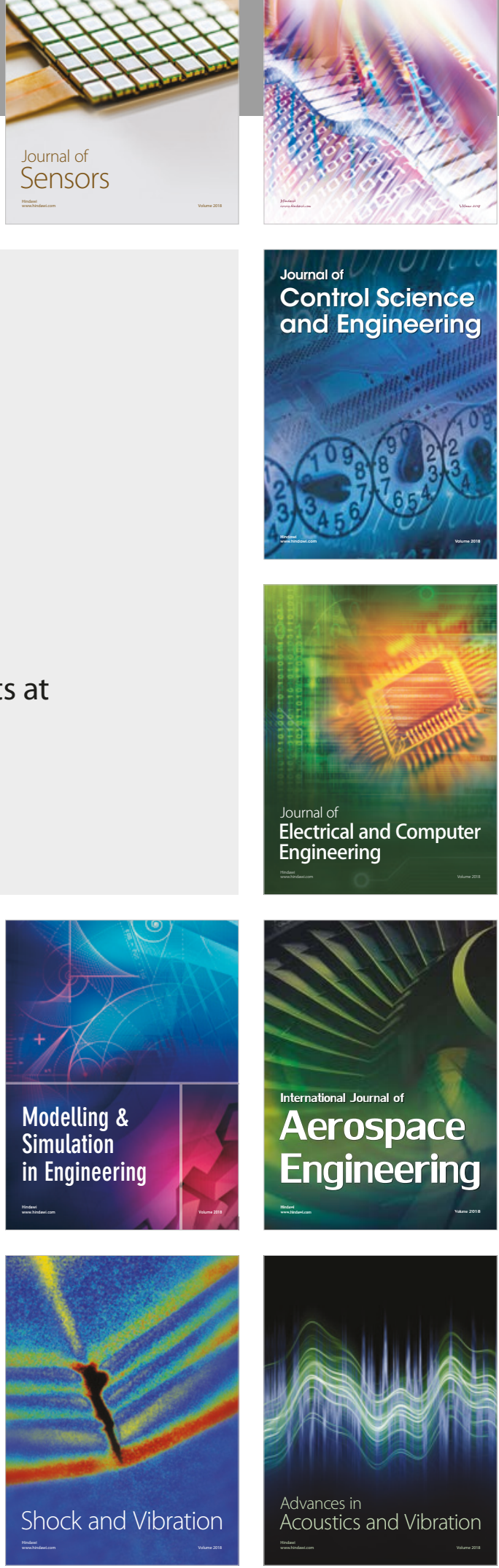